\title{
Caudal vena cava collapsibility index in healthy cats by ultrasonography
}

\author{
[Índice de colapsibilidade da veia cava caudal em gatos domésticos \\ Saudáveis, obtido por meio de ultrassonografia]
}

F.S. Alves ${ }^{l}$, F.G. Miranda ${ }^{l}$, R.Z. Rezende ${ }^{2}$, I.P. Souza ${ }^{l}$, R.C.S. Torres ${ }^{3}$, C.M.F. Rezende ${ }^{3}$, A.C. Nepomuceno ${ }^{3}$

\author{
${ }^{1}$ Aluna de pós-graduação - Escola de Veterinária - Universidade Federal de Minas Gerais - Belo Horizonte, MG \\ ${ }^{2}$ Residente em cirurgia - Universidade Federal do Rio Grande do Sul - Porto Alegre, RS \\ ${ }^{3}$ Escola de Veterinária - Universidade Federal de Minas Gerais - Belo Horizonte, MG
}

\begin{abstract}
The objective of this study was to calculate the collapsibility index (CI) in a group of 15 healthy adult mixed breed cats via right hepatic intercostal ultrasound view. The minimal and the maximal diameters of the caudal vena cava (CVC) were obtained during inspiration and expiration, respectively, then CI was calculated. The mean diameter of the CVC was $0.5 \mathrm{~cm}$. The mean CI was $28 \pm 3 \%$ and CI was not significantly associated with gender. As in human medicine, there is a growing need for less invasive monitoring in small animal practice. The CI enables the assessment of estimated volemia without the need for a central venous catheter. This is the first reported study investigating CI in cats.
\end{abstract}

Keywords: caval index, feline, ultrasound

\section{RESUMO}

O objetivo deste estudo foi calcular o índice de colapsabilidade (IC) em um grupo de 15 gatos adultos, saudáveis e SRD, por meio da janela ultrassonográfica hepática intercostal direita. Os diâmetros mínimo e máximo da veia cava caudal (VCC) foram obtidos durante a inspiração e a expiração, respectivamente. $O$ IC foi calculado, posteriormente. O diâmetro médio da VCC foi de 0,5cm. O diâmetro médio do IC foi de $28 \pm 3 \%$, e o IC não foi significativamente associado ao gênero. Como na medicina humana, há uma necessidade crescente de monitoramento menos invasivo na prática de pequenos animais. O IC possibilita a avaliação da volemia estimada sem a necessidade de um cateter venoso central. Este é o primeiro estudo relatado sobre IC em gatos domésticos.

Palavras-chave: índice caval, felina, ultrassom

\section{INTRODUCTION}

In veterinary medicine, central venous pressure (CVP) measurement is widely used in critically ill animals, more intensely in cases of hypovolemic or septic shock and in cases with renal or cardiac involvement. Despite this, its use for intravascular volume estimation has been questioned (Hutchison and Shaw, 2016; De Backer and Vincent, 2018). Central venous catheter placement is considered expensive and laborious and has been associated with a 39\% rate of complications such as infection and thrombosis in dogs and cats (Adamantos et al., 2010).
In some studies, with anesthetized dogs, the CVC diameter, measured by ultrasonography, has been used as a predictor of CVP (Nelson et al., 2010; Meneghini et al., 2016). Other studies have used the CVC diameter and/or the CVC diameter:aorta diameter ratio to assess blood volume in dogs (Cambournac et al., 2018; kwak et al., 2018). Recently, a study with healthy and spontaneously breathing dogs, reported that the right intercostal hepatic ultrasonographic view and a longitudinal right paralumbar ultrasonographic view can be used to obtain a reliable estimation of the CVC diameter. The authors were able to determine ultrasonographic reference intervals for the CVC

Recebido em 27 de março de 2019 
and aorta at three different anatomic locations (Darnis et al., 2018).

According to Tuplin et al. (2017), in healthy standing foals CVC was easily and consistently obtained during sonographic measurement and the significant variation between CVC diameters in inspiration and in expiration allowed the calculation of the CI. Bucci et al. (2017) investigated the ability of distensibility index of the caudal vena cava (CVCDI) to predict fluid response in healthy, anesthetized and mechanically ventilated dogs. The authors concluded that the CVCDI was higher in responders before volume expansion, however, this index demonstrated the worst performance as an index of fluid responsiveness when compared to systolic pressure variation and aortic flow peak velocity. The possible explanations might be measurement errors due to the influence of movements of the CVC during mechanical ventilation and that the ultrasound scanning of the CVC might be difficult in some individuals, contributing to the lower diagnostic performance.

The collapsibility of the inferior vena cava (IVC), in humans is an intravascular-volume status indicator. As intrathoracic pressure falls during inspiration, venous blood is pulled from the lower half of the body to the right atria. This results in a transient and normal reduction in the diameter of the IVC. As expiration occurs, the diameter returns to its basal size. These changes are known as respirophasic variation. The CI, also known as the caval index, is defined as the difference between the maximum (or expiratory) diameter and the minimum (or inspiratory) diameter divided by the maximum diameter (Seif et al., 2012).

The CVC diameter and CI have not yet been measured via ultrasonography in domestic cats, and these parameters may be useful for assessing volemia without the need for central-venous catheter placement. The objective of the current study was to determine the diameter and CI of the $\mathrm{CVC}$ via right hepatic intercostal ultrasound view in a group of 15 healthy adult mixed-breed domestic cats.

\section{MATERIALS AND METHODS}

Fifteen healthy adult mixed breed cats sourced from an animal facility under the animal ethics protocol number 148/2016 were used in the study.
The median weight of the cats was $4 \mathrm{~kg}$, the median age was 1 year, and 7 were female and 8 were male. The inclusion criterion were a clinically normal general condition and negative results for feline immunodeficiency virus and feline leukemia virus. A hemogram and iochemical profile were also performed, and no abnormalities were found. All the cats exhibited normal auscultation with cardiac and respiratory frequencies within the reference ranges for domestic cats. Because all the cats were healthy, we considered that CVP and systolic pressures were within the normal range $(0$ to $5 \mathrm{cmH} 2 \mathrm{O})$.

The equipment used for the measurements in all cats was a Mindray portable model M5, with a multi-frequency linear transducer $(7.5 \mathrm{MHz})$. The cats were restrained in the left lateral decubitus position and the measurements were taken by the same investigator via the right hepatic intercostal ultrasound view. By the use of ultrasound conductive gel, the transducer was placed parallel to the ribs in the intercostal space between the 10th and 11th ribs, approximately just below the epaxial muscles in the upper third of the thorax, allowing the CVC identification in transverse plane (Darnis et al.; 2018) (Figure 1). As recommended by Kamikawa (2009) and Darnis et al. (2018), biometric and hemodynamic evaluation was performed with minimal compression over the examined region because the CVC has thin walls.

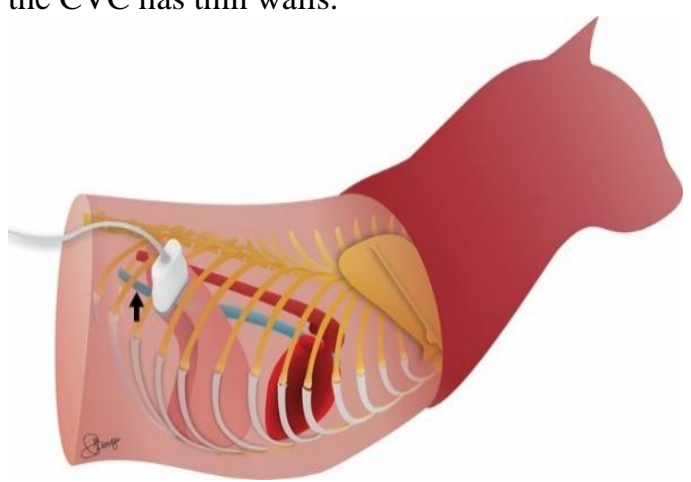

Figure 1. Schematic with demonstration of the probe positioning in right hepatic view, parallel to the ribs, in the intercostal space between the 10th and 11 th ribs, in order to identify the caudal vena cava (CVC) (black arrow)

The B-mode was used to obtain the anatomic location and to measure the diameter of the CVC in transverse plane, in millimeters ( $\mathrm{mm})$. In M-mode the minimal and maximal diameters of 
the CVC, in $\mathrm{mm}$, were obtained during spontaneous inspiration and expiration, respectively. These diameter values were then applied in the following formula for CI:

$\mathrm{CI}=((\mathrm{CVCmax}-\mathrm{CVCmin}) / \mathrm{CVC} \max ) \times 100$.

$\mathrm{CI}=((\mathrm{CVCmax}-\mathrm{CVCmin}) / \mathrm{CVC} \max ) \times 100$.

$\mathrm{CI}$ - colapsability indice

CVCmax - maximum CVC diameter, obtained during the spontaneous expiration

CVCmin - minimum CVC diameter, obtained during the spontaneous inspiration

There was no need for anesthesia then performing ultrasonographic measurements of the CVC diameters during inspiration and expiration. The cats used in the study had been handled since they were kittens, and therefore they were accustomed to human contact. The environment in which the ultrasonographic examinations were performed was duly regulated by maintaining silence and restricting the entry of people who were not required in order to perform the examination. For each cat used, bedding taken directly from their cage was placed on the examination table, to maintain a specific smell.

Statistical analyses were performed using $\mathrm{R}$ Studio software Version 0.99.902. Data sets were subjected to normality testing, then Student's ttest was performed to compare significant differences between gender. Pearson's correlational analysis was used to assess relationship normality testing, then Student's ttest was used. Pearson's correlational analysis was used to assess relationships between CI, and gender.

\section{RESULTS}

On B-mode, in the intercostal space between the 10 th and 11th ribs, the aorta was visualized dorsally, the CVC was visualized ventrally, and the portal vein was situated medially. These vessels were visualized in transverse planes with anechoic lumen and thin walls. The CVC diameter was measured in mm (Figure 2). In M-mode, the maximum and minimum diameters of the CVC were measured during spontaneous expiration and inspiration, respectively, and are represented in Figure 3.

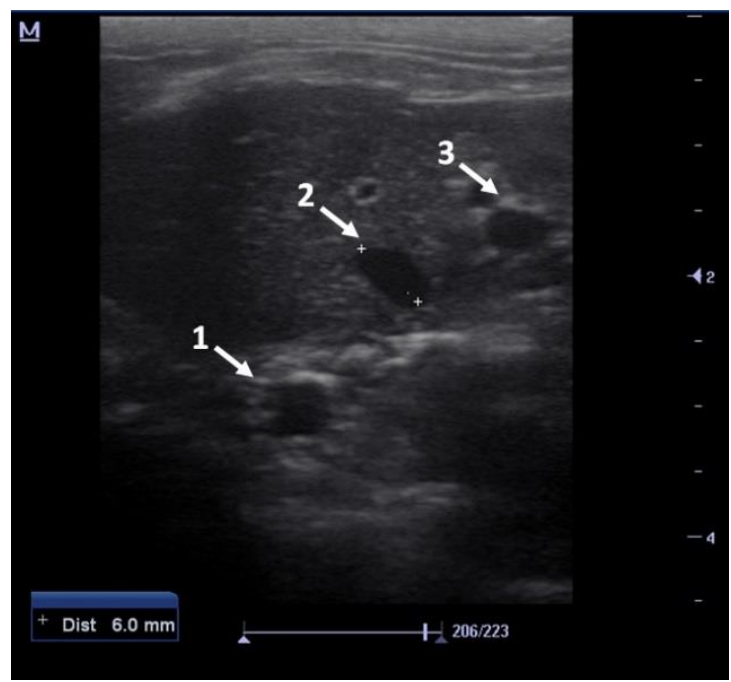

Figure 2. Ultrasonographic image in B-mode of a healthy adult mixed breed cat at one year of age. Vessels can be visualized in the right intercostal view, between the 10th and 11th ribs: aorta (1); caudal vena cava (2) and portal vein (3) in transverse planes. The cross signs delimit the caudal vena cava (CVC) diameter, which is $6.0 \mathrm{~mm}$ in this figure.

The results of measurements obtained for the diameter of the CVC in B-mode and for the CVC inspiratory and expiratory diameter ( $\mathrm{M}$ mode), and $\mathrm{CI}$ for the 15 mixed breed cats are listed in the table below (Table 1).

In B-mode, the overall mean diameter of the caudal vein (irrespective of respiratory phase and gender) was $5 \mathrm{~mm}$, with a $95 \%$ confidence interval of 3.9-7.1 mm. Males exhibited a slightly higher mean CI, but CI was not significantly associated with gender. In 5 cats some pauses were necessary before proceeding with the measurements equating to a difficulty rate of $33 \%$. 
B-MODE

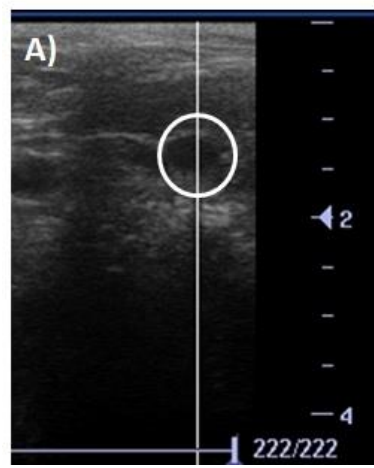

M-MODE

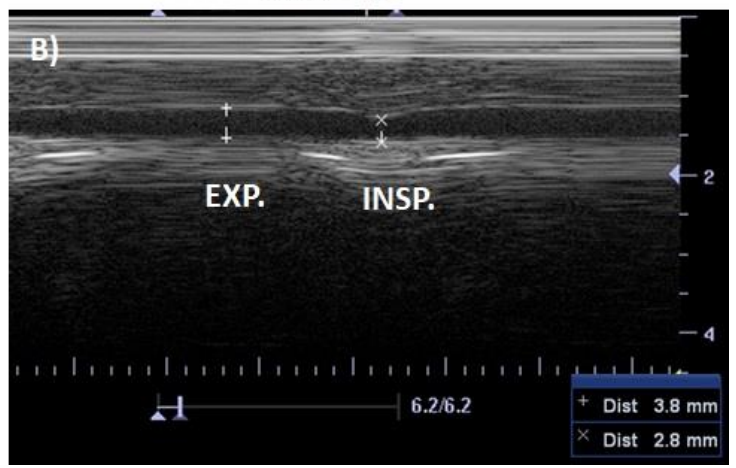

Figure 3. A) Cross-sectional ultrasonography of the caudal vena cava (white circle) obtained in B-mode in the intercostal space between the 10th and 11th ribs, of a healthy adult mixed breed cat. B) In M-mode, the maximum (++) and minimum (xx) diameters of the caudal vena cava were measured during spontaneous expiration (EXP.) and inspiration (INSP.), respectively.

Table 1. Diameters of the caudal vena cava (CVC) in B-mode, diameters of the CVC in inspiration and expiration in $\mathrm{M}$ - mode, and collapsibility index (CI) for the 15 mixed breed cats.

\begin{tabular}{|c|c|c|c|c|}
\hline Animal & $\begin{array}{l}\text { CVC diameter in } \\
\text { B-mode } \\
(\mathrm{mm})\end{array}$ & $\begin{array}{l}\text { CVC expiratory } \\
\text { diameter value } \\
(\mathrm{mm})\end{array}$ & $\begin{array}{l}\text { CVC inspiratory } \\
\text { diameter value } \\
(\mathrm{mm})\end{array}$ & CI $\%$ \\
\hline 1 & 4.2 & 4.53 & 3.83 & 16 \\
\hline 2 & 3.1 & 4.43 & 3.10 & 30 \\
\hline 3 & 4.1 & 3.80 & 2.73 & 28 \\
\hline 4 & 3.1 & 3.20 & 2.20 & 31 \\
\hline 5 & 5.9 & 6.17 & 4.77 & 23 \\
\hline 6 & 6.8 & 4.83 & 3.33 & 31 \\
\hline 7 & 6 & 3.90 & 3.03 & 24 \\
\hline 8 & 5.6 & 3.93 & 3.00 & 22 \\
\hline 9 & 5.8 & 3.60 & 2.70 & 25 \\
\hline 10 & 3.3 & 3.53 & 2.40 & 36 \\
\hline 11 & 3.8 & 4.10 & 2.77 & 33 \\
\hline 12 & 5.2 & 3.80 & 2.60 & 32 \\
\hline 13 & 6.2 & 6.17 & 4.73 & 23 \\
\hline 14 & 4.5 & 4.77 & 3.20 & 33 \\
\hline 15 & 15 & 5.33 & 3.80 & 29 \\
\hline Mean value & 5 & 4.40 & 3.21 & 28 \\
\hline
\end{tabular}

mm: millimeters/ CI: collapsibility index/ CVC: caudal vena cava

\section{DISCUSSION}

Right hepatic intercostal ultrasound view acquired in B-mode were considered useful for the measurement of CVC diameter in domestic cats with a mean age of 1 year in the current study, which agrees with previous studies in dogs (Meneghinni et al., 2016, Darnis et al., 2018; Kwak et al., 2018). Although the difficulty of performing ultrasound examinations in domestic cats was not very high in the present study (33\%) due to cat friendly practice and to the fact that the cats were used to handling. The cats used in the study were docile and accustomed to human contact, having been handled since they were kittens. The authors believe that the difficulty rate may be higher in cats that are fractious or highly stressed. Stress can lead to tachypnoea, making it difficult to locate vessels and to obtain adequate measurements.

One aspect that should be considered is that the type of difficulties associated with identifying the CVC may differ in different species. The 
difficulty encountered when performing ultrasonographic evaluation of some domestic cats $(33 \%)$ may be the duration of decubitus required. In foals, the depth of the image was reportedly increased in some cases to allow better identification of CVC due to the higher body weight of the species (Tuplin et al., 2017). In dogs, a commonly reported difficulty is the variability of body conformation, because in dogs with deep chests it is more difficult to find the portal vein - which is a necessary reference point for the location of the CVC. Another difficulty reportedly pertains to the substantial accumulation of gas in the right upper abdominal quadrant in some dogs (Darnis et al., 2018). The reported difficulties in foals and dogs were not observed in the cats of this study.

The mean CI in domestic cats was $28 \pm 3 \%$ in the present study, and there was no significant difference in CI between males and females. In a study that included 120 pediatric human patients, there was no significant correlation between gender and CI (Kuty et al., 2014). This suggests that gender may not affect CI in any of the species evaluated to date, including domestic cats. Notably however, a study involving a larger number of cats may detect a significant association between gender and CI. The mean CI of $28 \pm 3 \%$ in the domestic cats in the current study is similar to that of $30 \pm 13 \%$ previously reported in 120 pediatric human patients (Kuty et al., 2014) and $32.7 \%$ in human adults (Alavi-Moghaddam et al., 217). A mean CI of the CVC of $26 \pm 10 \%$ has been reported in foals (Tuplin et al., 2017), which is also similar to the CI obtained in domestic cats in the current study.

In the present study, the mean diameter of the $\mathrm{CVC}$ in cats was $0.5 \mathrm{~cm}$, which is close to the value of approximately $0.35 \mathrm{~cm}$ that has been reported in the puppies of small dog breeds (Kamikawa, 2009). It has been reported that the diameter of the CVC was approximately $1 \mathrm{~cm}$ in dogs of large breeds (Finn- Bodner e Hudson, 1998; Nelson et al., 2010).

The current study had some limitations. One relates to the evaluation of cats in a left lateral decubitus position. It is known that in humans the decubitus position influences CVC diameter, such that smaller diameters are reported in the left lateral decubitus (Ciozda et al., 2015). Similarly, although the cats in the present study exhibited normal auscultation with cardiac and respiratory rates that were within the normal reference values for the species, echocardiography was not performed, and the presence of undetected earlystage cardiac diseases that may have influenced CVC diameter and consequently the CI cannot be excluded.

Another limitation of this study consists in the fact that only one ultrasonografist collected all the measurements, hence it was not possible to report inter rate variability. Other possible ultrasonographic views to identify or evaluate the CVC were not performed.

\section{CONCLUSIONS}

Ultrasound examination can be used to estimate the CI of the CVC via the assessment of volemia without the need for a central venous catheter in healthy domestic cats. The CI determined in the present study may serve as a reference of normality in situations involving the intensive care of domestic cats in the future. The study is the first to investigate the $\mathrm{CI}$ of the $\mathrm{CVC}$ in domestic cats via right hepatic intercostal ultrasound view.

\section{REFERENCES}

ADAMANTOS, S.; BRODBELT, D.; MOORES, A.L. Prospective evaluation of complications associated with jugular venous catheter use in a veterinary hospital. J. Small Anim. Pract., v.51, p.254-257, 2010.

ALAVI-MOGHADDAM, M.; KABIR, A.; SHOJAEE, M. et al. Ultrasonography of inferior vena cava to determine central venous pressure: a meta-analysis and meta-regression. Acta. Radiol., v.58, p.537-541, 2017.

BUCCI, M.; RABOZZI, R.; GUGLIELMINI, C.; FRANCI, P. Respiratory variation in aortic blood peak velocity and caudal vena cava diameter can pre-dict fluid responsiveness in anaesthetised and mechanically venti-lated dogs. Vet. J., v.227, p.30-35, 2017.

CAMBOURNAC, M.; GOY-THOLLOT, I.; VIOLÉ, A. Sonographic assessment of volaemia: development and validation of a new method in dogs. J. Small Anim. Pract., v.59, p.174-182, 2018. 
CIOZDA, W.; KEDAN, I.; KEHL, D.W. et al. The efficacy of sonographic measurement of inferior vena cava diameter as an estimate of central venous pressure. Cardiovasc. Ultrasound, v.14, p.2-8, 2015.

DARNIS, E.; BOYSEN, S.; MERVEILLE, A.C. et al. Establishment of reference values of the caudal vena cava by fast-ultrasonography through different views in healthy dogs. J. Vet. Inter. Med., v.32, p.1308-1318, 2018.

DE BACKER, D.; VINCENT, J.L. Should we measure the central venous pressure to guide fluid management? Ten answers to 10 questions. Crit. Care, v.22, 2018.

FINN-BODNER, S.T.; HUDSON, J. Abdominal vascular sonography. Vet. Clinc. N. Am. Small Anim. Pract., v.28, p.887-941, 1998.

HUTCHINSON, K.M.; SHAW, S.P. A review of central venous pressure and its reliability as a hemodynamic monitoring tool in veterinary medicine. Top. Comp. Anim. Med., v.31, p.109-121, 2016.

KAMIKAWA, L. Veia cava caudal e vasos envolvidos no desvio portossistêmico congênito extra-hepático. In: CARVALHO, C.F. (Ed.). Ultrassonografia Doppler em pequenos animais. São Paulo: Roca, 2009. p.124-132.

KUTTY, S.; LI, L., HASAN, R. et al. Systemic venous diameters, collapsibility indices, and right atrial measurements in normal pediatric subjects. J. Am. Soc. Echocardiogr., v.72, p.155-162, 2014.
KWAK, J.; YOON, H.; KIM, J. et al. Ultrasonographic measurement of caudal vena cava to aorta ratios for determination of volume depletion in normal beagle dogs. Vet. Radiol. Ultrasound, v.59, p.203-211, 2018.

MENEGHINI, C.; RABOZZI, R.; FRANCI, P. Correlation of the ratio of caudal vena cava diameter and aorta diameter with systolic pressure variation in anesthetized dogs. Am. J. Vet. Res., v.77, p.137-143, 2016.

NELSON, N.C.; DROST, W.T.; LERCHE, P.; BONAGURA, J.D. Noninvasive estimation of central venous pressure in anesthetized dogs by measurement of hepatic venous blood flow velocity and abdominal venous diameter. Vet. Radiol. Ultrasound, v.51, p.313-323, 2010.

SEIF, D.; MAIHOT, T.; PERERA, P. et al. Caval sonography in shock: a noninvasive method for evaluating intravascular volume in critically ill patients. J. Ultrasound Med., v.31, p.1885-1890, 2012.

TUPLIN, M.C.; ROMERO, A.E.; BOYSEN, S.R. Influence of the respiratory cycle on caudal vena cava diameter measured by sonography in healthy foals: a pilot study. J. Vet. Intern. Med., v.31, p.1556-1562, 2017. 